\title{
Seat-belt Injuries
}

\author{
J. B. HAMILTON,* F.R.C.S.
}

Brit. med.7., 1968, 4, 485-486

\begin{abstract}
ummary: The drivers and passengers of two cars which collided head-on all wore lap and diagonal seatbelts. Three of the four suffered ruptured viscera and two incurred flexion-compression fractures of the neck. A victim of a traffic accident who was wearing a seatbelt and who has superficial bruising or pain presents a difficult diagnostic problem. Visceral injury should be suspected in such cases.
\end{abstract}

\section{Introduction}

It is generally accepted that the wearing of seat belts by car occupants reduces the likelihood of death or serious injury (Garrett and Braunstein, 1962). While a seat belt of good design properly worn will prevent the occupants of a car being flung violently against the steering-wheel, dashboard, or windscreen it must be accepted that the force applied to the body by the restraining effect of the belt is considerable. It is not surprising, therefore, that injuries directly due to the safety-belt occur.

Intra-abdominal injuries are much more frequent when only the lap type of strap is worn (Porter and Green, 1968), and, in fact, I can find no report of serious intra-abdominal injury where it is specifically stated that a safety-belt of the lap and diagonal pattern was worn.

Four cases are here reported because they all wore seat-belts of the currently approved lap and diagonal pattern (B.S.I. 3254). Three of them received severe intra-abdominal injury, and two of these also sustained flexion-compression injuries of the neck.

These four patients were injured in a road accident involving three cars. Car A was travelling on a major road at an estimated speed of 45 m.p.h. when it was struck on the near side by car B emerging from a side road. Car A was forced across the road by the impact, and came into head-on collision with car $\mathrm{C}$, travelling in the opposite direction on the major road. The driver of car $C$ also estimated his speed at 45 m.p.h.

The total number of persons involved was 13. Car A, in addition to the driver and front-seat passenger, contained their five children-aged $1 \frac{1}{4}, 5,7,8$, and 10 years-and their grandfather. The oldest child received facial lacerations from broken glass, while the next oldest had a scalp wound. The other occupants were unhurt. In car $B$ the driver was unhurt and the back-seat passengers suffered facial bruising. In car $\mathrm{C}$ a 3-yearold child sustained a fracture of the shaft of the left femur. All of these cases were admitted to a peripheral hospital on 1 June 1968.

\section{Case 1}

This patient, the driver of car A, aged 36, complained of abdominal pain and pain in his mouth on admission. His incisor teeth were so loosened that extraction was necessary. A bruise $5 \mathrm{~cm}$. wide was noted over the right biceps muscle, extending downwards and to the left over the right side of the chest, the right hypochondrium, and the umbilical region. Palpation of the abdomen revealed tenderness in the periumbilical area in the line of the bruise. Rebound tenderness was absent and bowel sounds were normal. Blood pressure was $120 / 80$, pulse $90 / \mathrm{min}$. No peripheral injuries were noted and no fractures were revealed on radiological examination.

* Lurgan and Portadown Hospital, Lurgan, County Armagh, N. Ireland.
Routine observations were made by the nursing staff, and the patient was re-examined at regular intervals by the duty surgeon. Thirty hours after the accident he began to show signs of peripheral vasoconstriction but there was little change in pulse or bloodpressure readings. The abdomen was slightly distended, with some tenderness, but bowel sounds were normal.

On laparotomy a tear $1 \mathrm{~cm}$. long sealed with omentum was found in the jejunum $50 \mathrm{~cm}$. from the duodenojejunal flexure. Free fluid was present, with only minimal soiling by intestinal contents. The jejunal tear was oversewn in two layers with catgut.

Thorough examination of the remainder of the abdominal contents revealed considerable bruising of much of the jejunal wall. The wound was closed, with drainage to the left subphrenic area and to the left iliac fossa.

His recovery was complicated by an abscess in the left iliac fossa that required drainage. Peristalsis was very slow to return, and some 10 days elapsed before he could tolerate oral fluids. The case can be described as rupture of the jejunum due to pressure of a seat belt.

\section{Case 2}

This married woman, aged 34, a front-seat passenger in Car A, was admitted complaining of severe pain in her neck and slight pain in her abdomen. Bony injury to the neck was suspected, and radiographs of the skull and cervical spine showed a fracture of the posterior arch of the atlas and fractures of the pedicles of the axis. The atlas was dislocated anteriorly on the axis. There was also a fracture-dislocation at C6-C7. Her nose was broken. There were fractures of the left third and fourth ribs in the nipple line. No neurological signs were present to suggest cord compression. A tiny laceration on the frontal region suggested a minor blow.

General examination revealed a bruise from the left clavicle to the right side of the abdomen corresponding to the line of the diagonal belt, and also a transverse bruise at the level of the umbilicus caused by the lap belt. Minimal tenderness over the centre of the abdomen was elicited. Bowel sounds were normal and deep palpation was readily tolerated by the patient. She was transferred at once to the fracture unit of the Royal Victoria Hospital, where skull traction was applied.

Over the next three days she was observed carefully as her abdominal tenderness persisted, but she was tolerating liquids and semisolids well and the abdomen remained soft and only slightly tender. Bowel sounds were normal.

On the evening of the fourth day after the accident the patient complained of increasing abdominal pain and suddenly became shocked. Laparotomy was carried out and a retroperitoneal pseudocyst due to posterior injury to the third part of the duodenum was found to have ruptured into the peritoneal cavity. There was some bruising of the bowel wall but nothing else of importance was noted. The defect was repaired and the abdomen closed.

She made an uncomplicated recovery from this operation, and there have been no neurological findings to suggest cervical cord damage.

\section{Case 3}

This man, the driver of car C aged 32, complained of pain in his shoulders and neck. On examination he was unmarked and clinically no injury was detected. $X$-ray examination of skull, cervical, and thoracic spine and rib cage revealed only undisplaced fractures of the anterior ends of the third and fourth ribs on the left side.

He was kept under observation for four days and was then allowed to go home. 


\section{Case 4}

This patient, a married woman aged 25 , a front-seat passenger, complained of pain in the chest, abdomen, and both knees. On examination there was a right periorbital haematoma, deep transverse lacerations of both knees approximately $5 \mathrm{~cm}$. in length, and a comminuted fracture of the right patella. Clothing and first-aid dressings were saturated with blood from the left knee, which was still bleeding freely on admission. There was some generalized abdominal tenderness, but no rebound tenderness or rigidity. No belt mark was noted.

Blood pressure was $80 / 50 \mathrm{~mm}$. $\mathrm{Hg}$ and pulse $120 / \mathrm{min}$. Blood loss from the bleeding was difficult to estimate, but from the report of the ambulance crew it was judged to be sufficient to account for the hypotension. The patient stated that she habitually suffered from dysmenorrhoea and had experienced it that morning before the accident.

She was given a transfusion of two pints $(1,140 \mathrm{ml}$.) of blood, during which her blood pressure rose to $115 / 80$ and remained there. She was closely observed for the next 24 hours, and by which time she no longer complained of abdominal pain and no tenderness was elicited on palpation. Bowel sounds were normal.

$X$-ray examination of skull, spine, chest, and lower limbs revealed a flexion-compression fracture of $\mathrm{T} 1$ and confirmed the presence of a comminuted fracture of the right patella. Forty-eight hours after the accident the patella was excised and the leg encased in plaster-of-Paris.

Next day the patient was feeling very well and asked to be transferred to another hospital 20 miles $(32 \mathrm{~km}$.) away which was near to her home ; this was arranged. On the afternoon of the fourth postoperative day she began to have severe abdominal pain, with rebound tenderness and distension.

Laparotomy was carried out and a retroperitoneal abscess due to a tear in the anterior wall of the third part of the duodenum was found. There was also marked distension of the ascending and transverse colon, and a caecostomy was carried out. About $250 \mathrm{ml}$. of heavily blood-stained free fluid was found and there was a $2-\mathrm{cm}$. tear in the splenic capsule. Splenectomy was performed. Recovery was uneventful, the caecostomy sealing rapidly after removal of the tube.

\section{Discussion}

The concept that a car occupant may be injured in a crash by the safety-belt he wears for protection is now accepted, and the list of injuries reported is impressive (Aiken, 1963); Sube et al., 1967). Rupture of great vessels, perforation of small bowel, rupture of spleen, duodenum, and pancreas, tearing of bowel mesentery, and rupture of the gravid uterus have all been recorded, as well as less serious injuries such as contusion of the small bowel and the delayed formation of adhesions.

However, remarkably little has been published on the subject of seat-belt injuries, and what has appeared seems to have been confined to injuries due to the single lap-strap type of belt. Many authors do not specify the type of belt worn, but as most of the reports emanate from America it is to be assumed that this type of strap, prevalent in that country and described in other papers, is the one referred to. I have not found any reports specifically describing serious abdominal injuries due to the lap and diagonal belt. It is therefore particularly interesting that of the above four people, all wearing the latter type of belt, three sustained severe abdominal injuries, and two of these had flexion-compression injuries. The subjects of case histories 1 and 2 stated that their belts were not obtained specifically for their make of car and were difficult to adjust correctly. In fact, in Case 1 the diagonal strap was so loose that it had slipped from the patient's shoulder and lay across his upper arm before the impact. The importance of correct positioning of the belt cannot be exaggerated, and has also been stressed by Cocke and Meyer (1963).

Injury to abdominal viscera has been attributed to compression between the safety-belt and the vertebral column (Williams and Sargent, 1963). Considerable shearing forces would act particularly on the less mobile viscera, such as the duodenum, producing transection or perforation as in Cases 2 and 4 . The compression of a loop of bowel distended with fluid may cause perforation even of a mobile segment of bowel. An instance of jejunal tear similar to that in Case 1 has been reported (Tolins, 1964). It may be that the bruising of the anterior abdominal wall noted in two of the patients was produced by the same mechanism. The yielding abdominal wall appears capable of absorbing blows of considerable force, as from fist or boot, without evidence of bruising. The presence of bruising might therefore suggest that, by the pressure of the belt, the anterior abdominal wall had been driven back sufficiently to be compressed against the vertebral column. In such circumstances injury to abdominal viscera is probable, and must be suspected until the reverse can be proved.

However, in Case 4, and in reports by the other writers referred to, intra-abdominal injuries have been present in the absence of external marks of any kind, and with minimal complaint from the patient. This form of presentation is obviously much more deceptive, for the positive exclusion of visceral catastrophe can be exceedingly difficult. Haemorrhage from a large vessel or a vascular organ rapidly becomes apparent. Perforation of the bowel, on the other hand, may pursue a most insidious course, making diagnosis almost impossible. Days after the accident the patient may still be feeling well and tolerating food, while clinical examination may reveal nothing abnormal. One case is on record where laparotomy was not undertaken for 13 days (Fish and Wright, 1965). When such an injury is associated with other serious trauma-head injury leading to prolonged unconsciousness, or quadriplegia due to spinal injury -as might easily have been the lot of Case 2 above, the possibility of diagnosis is remote, and the prognosis correspondingly poor.

It is of interest to note that both front-seat passengers (Cases 2 and 4) sustained flexion-compression fractures of the neckone serious and causing severe pain, the other less serious and producing no symptoms whatever. The latter injury was discovered only as a result of systematic $x$-ray examination.

In the light of the above experience it is essential that casualty officers bear in mind the possibility of serious skeletal or visceral injury in victims of car accidents even when safetybelts of the officially approved pattern have been worn. The importance of excluding serious injury cannot be overstressed, and it must be realized that physical examination alone is totally inadequate for this purpose. Routine $x$-ray examination of the skeleton is essential, particularly of the skull and spine, while any patient who has suffered external violence to the abdomen merits close observation and repeated reassessment for a minimum of 48 hours.

The finding of cutaneous bruising of the anterior abdominal wall or the continued presence of even slight abdominal pain should be regarded as an indication for laparotomy.

While the idea of this paper was to draw attention to the possibility of injury due to the wearing of safety-belts, it should not be interpreted as an argument in favour of abandoning the practice. Published data point overwhelmingly to the advantages of safety-belts. Though injuries directly due to safetybelts are possible there is nothing to suggest that the injuries would have been less severe had a belt not been worn.

I wish to thank Mr. H. W. C. Bailie, Mr. W. S. Hanna, Mr. E. Morrison, and Mr. R. I. Wilson for permission to publish these cases, and also the last-named for his help and advice on the preparation of this article.

\section{REFERENCES}

Aiken, D. W. (1963). 7. La. med. Soc., 115, 235.

Cocke, W. M., and Mayer, K. K. (1963). F. Amer. med. Ass., 183, 693.

Fish, J., and Wright, R. H. (1965). Ұ. Trauma, 5, 746.

Garrett, J. W., and Braunstein, P. W. (1962). F. Trauma, 2, 220

Garrett, J. W., and Braunstein, P. (1968). Arch. Surg., 96, 242.
Porter, S. D., and Green, E. W. Surg., 113, 346.

Tolins, S. H. (1964). 7. Trauma, 4, 397.

Williams, R. D., and Sargent, F. T.'(1963). F. Trauma, 8, 288. 